\title{
YBX1 gene silencing inhibits migratory and invasive potential via CORO1C in breast cancer in vitro
}

Jia Pei Lim ${ }^{1,2}$, Sukanya Shyamasundar ${ }^{1}$, Jayantha Gunaratne ${ }^{1,2}$, Olivia Jane Scully ${ }^{1}$, Ken Matsumoto ${ }^{3}$ and Boon Huat Bay ${ }^{1 *}$

\begin{abstract}
Background: Y-box binding protein-1 is an evolutionary conserved transcription and translation regulating protein that is overexpressed in various human malignancies, including breast cancer. Despite reports of YB-1 and its association with distant spread of breast cancer, the intrinsic mechanism underlying this observation remains elusive. This study investigates the role of YB-1 in mediating metastasis in highly invasive breast cancer cell lines.

Methods: Silencing the YBX1 gene (which encodes the YB-1 protein) by small interfering RNA (siRNA) was performed in MDA-MB-231 and Hs578T breast cancer cell lines, followed by phenotypic assays including cell migration and invasion assays. Gene expression profiling using Affymetrix GeneChip ${ }^{\oplus}$ Human Transcriptome 2.0 array was subsequently carried out in YB-1 silenced MDA-MB-231 cells. Overexpression and silencing of YBX1 were performed to assess the expression of $\mathrm{CORO1C}$, one of the differentially regulated genes from the transcriptomic analysis. A Gaussia luciferase reporter assay was used to determine if CORO1C is a putative YB-1 downstream target. siRNA-mediated silencing of CORO1C and down-regulation of YBX1 in CORO1C overexpressing MDA-MB-231 cells were performed to evaluate cell migration and invasion.

Results: Downregulation of the YB-1 protein inhibited cell migration and invasion in MDA-MB-231 breast cancer cells. Global gene expression profiling in the YBX1 silenced MDA-MB-231 cells identified differential expression of several genes, including CORO1C (which encodes for an actin binding protein, coronin-1C) as a potential downstream target of YB-1. While knockdown of YBX1 gene decreased CORO1C gene expression, the opposite effects were seen in YB-1 overexpressing cells. Subsequent verification using the reporter assay revealed that CORO1C is an indirect downstream target of YB-1. Silencing of CORO1C by siRNA in MDA-MB-231 cells was also observed to reduce cell migration and invasion. Silencing of $Y B X 1$ caused a similar reduction in CORO1C expression, concomitant with a significant decrease in migration in Hs578T cells. In coronin-1C overexpressing MDA-MB-231 cells, increased migration and invasion were abrogated by YB-1 knockdown.
\end{abstract}

Conclusion: It would appear that YB-1 could regulate cell invasion and migration via downregulation of its indirect target coronin-1C. The association between YB-1 and coronin-1C offers a novel approach by which metastasis of breast cancer cells could be targeted and abrogated.

Keywords: YB-1 protein, CORO1C gene, Migration, Invasion, Metastasis, Breast cancer

\footnotetext{
*Correspondence: boon_huat_bay@nuhs.edu.sg

${ }^{1}$ Department of Anatomy, Yong Loo Lin School of Medicine, National

University of Singapore, 4 Medical Drive, Blk MD10, Singapore 117594,

Singapore

Full list of author information is available at the end of the article
} International License (http://creativecommons.org/licenses/by/4.0/), which permits unrestricted use, distribution, and reproduction in any medium, provided you give appropriate credit to the original author(s) and the source, provide a link to the Creative Commons license, and indicate if changes were made. The Creative Commons Public Domain Dedication waiver (http://creativecommons.org/publicdomain/zero/1.0/) applies to the data made available in this article, unless otherwise stated. 


\section{Background}

Breast cancer is the leading cancer that affects women around the world, where the majority of deaths due to this dreaded disease could be attributed to metastasis. The World Health Organisation (WHO) has ranked breast cancer as the most common cause of cancerrelated deaths in women in 2012, accounting for approximately $14.3 \%$ of cancer-related mortality in less developed countries [1]. Metastasis involves the invasion of cancer cells from the primary tumour site to the surrounding extracellular matrix and stroma, from wherein the cancer cells intravasate, travel through the vasculature and extravasate to form a secondary tumour at a distant site [2]. It is estimated that approximately $10-15 \%$ of breast cancer patients, show evidence of distant metastasis within 3 years from the initial detection of the primary tumour [3]. However, in some breast cancer patients, metastasis occurs after 10 years from the initial presentation of the primary tumour [4]. Furthermore, the heterogeneous nature of breast cancer makes it difficult for identification of patients who are at risk of developing metastasis.

Recent research has shed light on a potential biomarker for early metastasis, namely Y-box binding protein-1 (YB-1) encoded by the $Y B X 1$ gene. YB-1 is an evolutionary conserved protein with a cold-shock domain, and is crucial to many fundamental cellular processes, including transcription and translation regulation [5]. Elevated YB-1 has been observed in many human malignancies, such as prostate cancer [6], gastric cancer $[7,8]$ and nasopharyngeal cancer [9]. YB-1 overexpression has been found be an independent prognostic marker in breast cancer [10]. Overexpression of YB-1 in the mammary gland of a novel transgenic mouse model showed that YB-1 induced genetic instability, leading to breast cancer [11]. In addition, YB-1 is involved in the upregulation of the transcription of multidrug resistance 1 (MDR1) gene which encodes for P-glycoprotein, a protein which mediates chemoresistance $[12,13]$. YB-1 also contributes to enhanced membrane type I-matrix metalloproteinase (MT1-MMP) activity in MCF7 breast cancer cells, thus inducing tumor invasion and metastasis [14]. Moreover, YB-1 has been observed to potentiate epithelial to mesenchymal transition (EMT), possibly through the elevated translation of Snail1, which is an important mediator of the EMT process, and eventually leading to enhanced metastasis [15].

This study attempts to elucidate the role of YB-1 in mediating the metastatic cascade, through manipulation of YB-1 expression in aggressive MDA-MB-231 and Hs578T breast cancer cells. Gene expression profiling revealed that knockdown of YB-1, inhibited migratory and invasive potential with altered expression of several genes, in invasive MDA-MB-231 cells. Functional annotation clustering using the DAVID analysis, demonstrated that these differentially expressed genes are important for the cytoskeletal pathway, including CORO1C which encodes coronin-1C, an actin-binding protein. siRNA mediated silencing of CORO1C in MDA-MB231 cells was observed to decrease cell migration and invasion (similar to YB-1 silenced cells). Similar findings were also observed in Hs578T breast cancer cells. Furthermore, transient overexpression of coronin-1C resulted in increased cell migration and invasion, which was abrogated by YB-1 knockdown in MDA-MB-231 cells. We show for the first time that YB-1 could regulate cell invasion and migration, possibly via regulation of its downstream target coronin-1C.

\section{Methods}

Cell culture

The human MDA-MB-231 breast cancer cell line (ATCC ${ }^{ø}$ HTB-26 ${ }^{\text {tM }}$ ) was cultured in RPMI 1640 medium, which contained $10 \%$ fetal bovine serum (FBS). Hs578T breast cancer cells (ATCC ${ }^{\oplus}$ HTB-126 ${ }^{\mathrm{TM}}$ ) were propagated in DMEM medium with $10 \%$ FBS and supplemented with $50 \mu \mathrm{g} / \mathrm{ml}$ insulin (Sigma-Aldrich, St. Louis, MO, USA).

\section{Short interfering RNA (siRNA) transfection}

$2.5 \times 10^{5}$ MDA-MB-231 cells and $1 \times 10^{5}$ Hs578T cells were seeded in each well of a 6-well plate, a day prior to siRNA transfection. The ON-TARGETplus SMARTpool siRNA (GE Dharmacon, Pitssburgh, PA, USA), consisting of 4 individual siRNA targeting $Y B X 1$ or CORO1C were used. A non-targeting siRNA was used as the negative control (siNeg). Triplicate wells were seeded for each of the siRNA. The transfection was carried out following the manufacturer's protocol. Briefly, a final concentration of $20 \mathrm{nM}$ for each of the siRNA was added together with the transfection reagent DharmaFECT (GE Dharmacon). The cells, together with the transfection mixture were incubated for $24 \mathrm{~h}$, after which they were replenished with fresh medium. Cells were grown for $48 \mathrm{~h}$ and $72 \mathrm{~h}$ after transfection for RNA extraction and protein extraction respectively.

\section{Quantitative real-time polymerase chain reaction (qPCR)}

After extraction of total RNA with the RNeasy Mini extraction kit (Qiagen, Hilden, Germany), $1 \mu \mathrm{g}$ of total RNA was converted to first strand cDNA using the SuperScript III First-Strand synthesis system (Invitrogen, Carlsbad, CA, USA). Gene expression of $Y B X 1$ and CORO1C were subsequently quantified in an Applied Biosystems 7900HT Fast Real-Time PCR system using the Fast SYBR Green Master Mix (Applied Biosystems, Foster City, CA, USA). Each sample was run in triplicates and GAPDH was used as the housekeeping gene 
for normalisation. Alterations in gene expression were expressed as fold change using the $2^{-\Delta \Delta C T}$ method [16]. The primers used are listed in Additional file 1: Table S1.

\section{Western blot}

Whole cell lysates were extracted using a mixture of radio-immunoprecipitation (RIPA) lysis buffer (Pierce, Waltham, MA, USA), Halt Protease and Phosphatase Inhibitor Cocktail (Pierce) and 0.5 ethylenediaminetetraacetic acid (EDTA) (Pierce) on ice for $15 \mathrm{~min}$. After cell lysis, the lysates were centrifuged for $15 \mathrm{~min}$ at $21,000 \mathrm{~g}$, $4{ }^{\circ} \mathrm{C}$. Protein concentration was determined using the microtiter Bio-Rad Protein Assay (Bio-Rad, Hercules, CA, USA). The same amount of protein lysates were denatured at $95^{\circ} \mathrm{C}$ in $5 \mathrm{X}$ loading dye for $5 \mathrm{~min}$ and loaded into each well of the $10 \%$ sodium dodecyl sulfatepolyacrylamide gel. After separation by electrophoresis, proteins were transferred to a polyvinyl difluoride (PVDF) membrane using a semi-dry system (Bio-Rad). Transfer of proteins was carried out at $20 \mathrm{~V}$ for $1 \mathrm{~h}$. Blocking of the PVDF membrane was subsequently done using 5\% skim milk, followed by incubation with primary antibodies that include anti-coronin-1C (1:1000 dilution) (Abnova, Taipei City, Taiwan), anti-HIPK3 (1:5000) (Abcam, Cambridge, UK), anti-SLAIN2 (1:1000 dilution) (Abcam), anti-YB-1 (1:1000 dilution) [9] and anti- $\beta$-actin (1:6000 dilution) (Sigma-Aldrich) at $4{ }^{\circ} \mathrm{C}$ overnight. Subsequently, incubation with the HRPconjugated secondary antibody (Sigma-Aldrich) was carried out for $1 \mathrm{~h}$ at room temperature. The SuperSignal West Pico Chemiluminescent ECL substrate (Pierce) was used to detect the protein bands which were then quantified using the GS-800 densitometer (Bio-Rad).

\section{Cell migration and cell invasion assays}

Transwell migration assay was performed by using polycarbonate membrane transwell inserts (Corning, NY, USA), with a membrane diameter of $8.0 \mu \mathrm{m}$. A BD BioCoat $^{\text {tw }}$ Matrigel ${ }^{\mathrm{me}}$ Invasion Chamber (BD Biosciences, San Jose, CA, USA) with an $8 \mu \mathrm{m}$ pore size Polyethylene Terephthalate membrane, was used for the cell invasion assay. $48 \mathrm{~h}$ post-transfection with siRNA, 20,000 cells/ well or 30,000 cells/well were seeded in triplicates in the upper chamber for the transwell migration or invasion respectively for MDA-MB-231 cells. For Hs578T cells, 10,000 cells/well and 20,000 cells/well were seeded and incubated for $18 \mathrm{~h}$ or $20 \mathrm{~h}$, for the migration and invasion assays respectively. After which, the migratory or invasive cells were fixed with absolute methanol for $15 \mathrm{~min}$, washed twice and stained with $0.5 \%$ crystal violet in water for $20 \mathrm{~min}$. Removal of excess crystal violet stain was carried out by dipping the upper chamber inserts in distilled water and wiped away with cotton swabs from the upper membrane of the inserts. A Nikon
SMZ 1500 stereo microscope at 10X magnification was subsequently used to view the stained cells. Five different fields were imaged and the average number of cells per insert was counted. Experiments were performed in triplicates.

\section{Gene microarray}

To determine potential targets of YB-1 in MDA-MB-231 cells, global gene expression profiling was performed using Affymetrix GeneChip Human Transcriptome 2.0 Array (Affymetrix, Santa Clara, CA, USA). Briefly, $100 \mathrm{ng}$ of RNA was reverse transcribed to generate double stranded cDNA that was amplified to produce cRNA. The cRNA generated was purified and subjected to 2nd -cycle single stranded sense cDNA that was fragmented, labelled and hybridized to Affymetrix GeneChip ${ }^{\circ}$ Human Transcriptome 2.0 array. The arrays were washed, stained and scanned using the Affymetrix $30007 \mathrm{G}$ scanner. The differentially expressed genes between siNeg and siYB-1 transfected cells were determined using a fold change cut-off at 2 and $p<0.05$ with the Transcriptome Analysis Console 3.0 software and annotation file HTA-2_0.na36.hg19.transcript.csv available from Affymetrix. Functional annotation clustering of the differentially expressed genes was carried out using the Database for Annotation, Visualization and Integrated Discovery (DAVID).

\section{Transfection of YB-1 overexpression plasmid}

A cell density of $2.5 \times 10^{5}$ MDA-MB-231 cells was plated in each well of a 6-well plate, a day prior to plasmid transfection. The following day, the cells were transfected with $2 \mu \mathrm{g}$ of pCMV6-AC-YBX1-GFP overexpression plasmid which encodes the ORF of $Y B X 1$ gene (Origene, Rockville, MD, USA) or the pCMV6-AC-GFP empty vector control (Origene) using $6 \mu \mathrm{l}$ of TurboFectin 8.0 (Origene) per well. The transfected cells were then incubated for $72 \mathrm{~h}$ for protein isolation. Experiments were performed in triplicate wells for each plasmid.

\section{Gaussia luciferase reporter assay}

Gaussia luciferase reporter constructs containing the promoter region of CORO1C gene and a negative promoter region (both from Genecopoeia, Rockville, MD, USA) were used. $2.5 \times 10^{5}$ MDA-MB-231 cells were seeded per well in a 6-well plate and co-transfected with $20 \mathrm{nM}$ of siNeg or siYB-1 with $1 \mu \mathrm{g}$ of CORO1C promoter reporter construct, using Lipofectamine 2000 (Invitrogen). Also, $1 \mu \mathrm{g}$ of negative promoter construct was used in place of the CORO1C promoter reporter construct and co-transfected with $20 \mathrm{nM}$ of siYB-1. The co-transfections were done in triplicates. Media was changed $24 \mathrm{~h}$ post transfection. Subsequently, the cell culture supernatant was collected from each well $48 \mathrm{~h}$ post transfection and the Gaussia luciferase (GLuc) and secreted alkaline phosphatase (SEAP) activities were 
assessed using the Secrete-Pair Dual Luminescence Assay Kit (Genecopoeia), in triplicates with 1500 ms integration time. Normalised data (relative luminescence unit, RLU) was calculated as the ratio of GLuc/SEAP activities from the triplicate readings. The average RLU was calculated from an average of the normalised data for the triplicate transfected wells.

In addition, MDA-MB-231 cells were co-transfected with $1 \mu \mathrm{g}$ of $C O R O 1 C$ promoter reporter construct and $1 \mu \mathrm{g}$ of YB-1 ORF construct (pCMV6-AC-YBX1-GFP) or empty vector construct (pCMV6-AC-GFP) in a 6-well plate using TurboFectin 8.0 (Origene), in accordance with the manufacturer's protocol. $1 \mu \mathrm{g}$ of negative promoter construct was also used in place of $\mathrm{CORO1C}$ promoter reporter construct and co-transfected with $1 \mu \mathrm{g}$ of YB-1 ORF plasmid. After which, the same procedure as mentioned above was repeated.

\section{Co-transfection of siRNA and plasmid DNA}

$6 \times 10^{4}$ MDA-MB-231 cells were seeded in each well of a 24-well plate. The following day, cells were transfected with $200 \mathrm{ng}$ of pCMV6-AC-GFP empty vector control

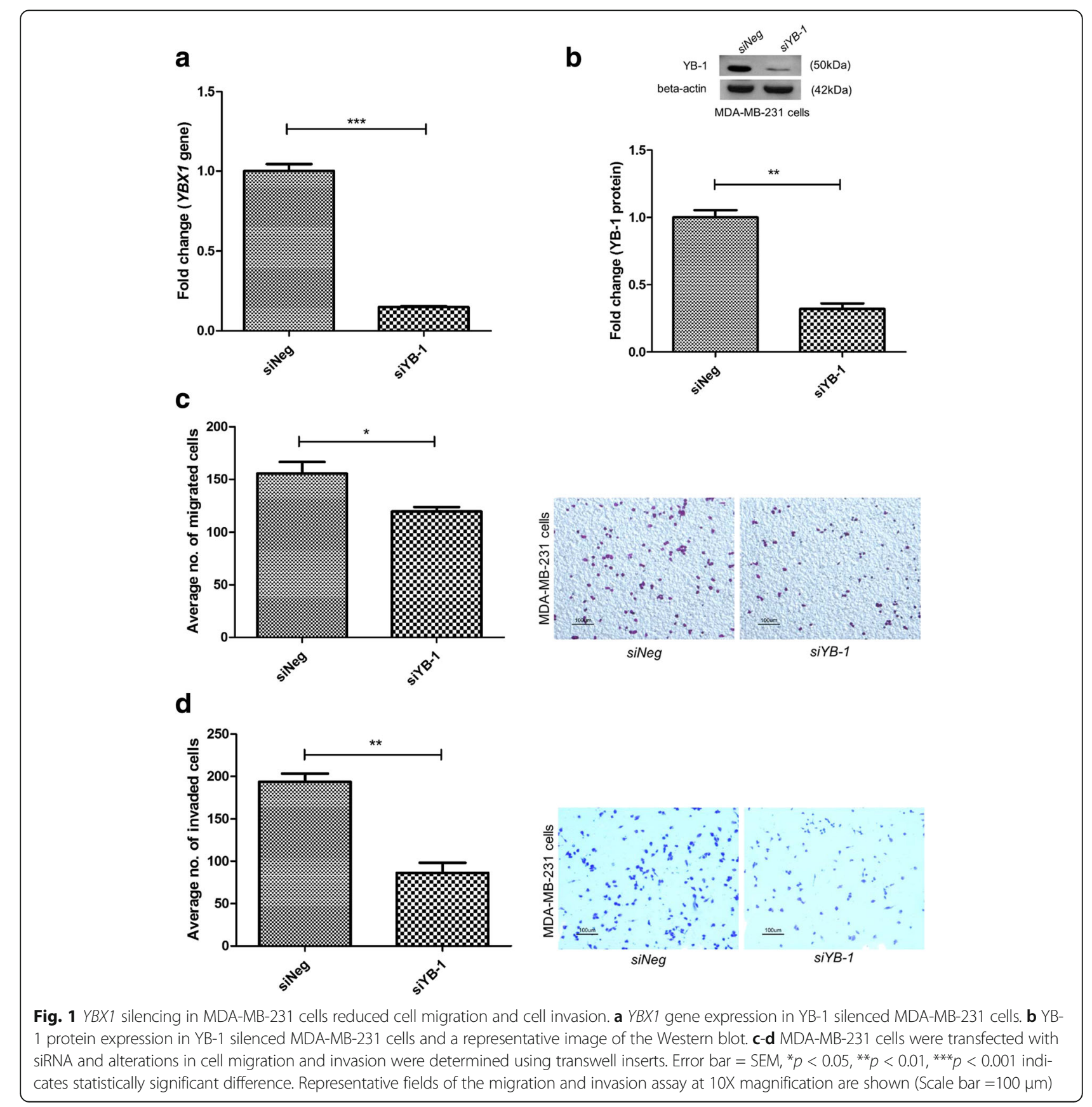


(Origene) or CORO1C ORF construct (pCMV6-ACCORO1C-GFP) (Origene) with $1 \mu \mathrm{l}$ of Lipofectamine 3000 and $0.8 \mu$ lof P3000 (Invitrogen), according to the manufacturer's protocol and incubated overnight. Subsequently, the cells were transfected with siNeg or siYB-1 siRNA to a final concentration of $20 \mathrm{nM}$ per well using DharmaFECT (GE Dharmacon) as described above. The cells were incubated for an additional of $48 \mathrm{~h}$ before seeding for migration or invasion assay.

\section{Statistical analyses}

The GraphPad Prism 5.0 was used for analyses. Data was analyzed with two-sided unpaired Student's t-test for samples with two groups and One-way ANOVA for samples with more than two groups. All values are represented as mean \pm SEM. The results were considered statistically significant when $p$ is $<0.05$.

\section{Results}

Downregulation of YB-1 protein decreased cell migration and invasion

To evaluate YB-1 function in breast cancer metastasis, silencing of the $Y B X 1$ gene by siRNA was carried out in MDA-MB-231 breast cancer cells. The silencing effciency of the $Y B X 1$ gene was approximately $85.1 \%$ in the siYB-1 cells (Fig. 1a), while at the protein level, YB-1

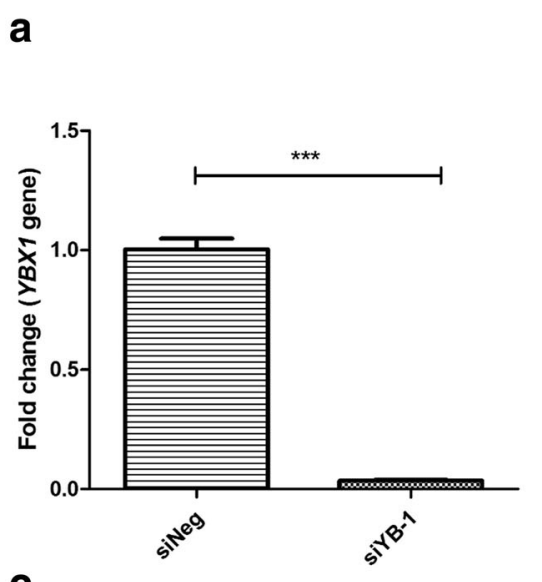

b
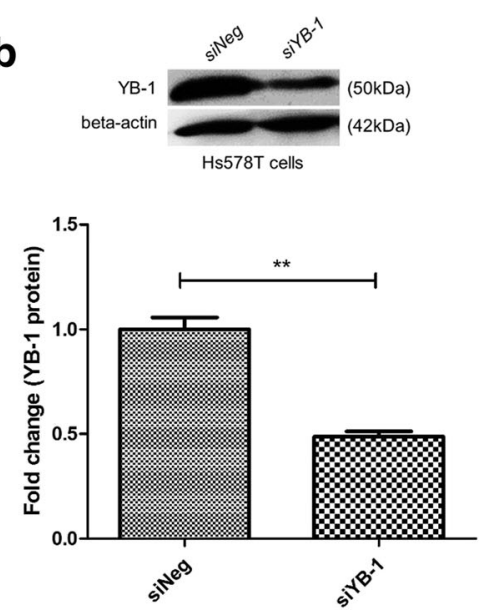

C
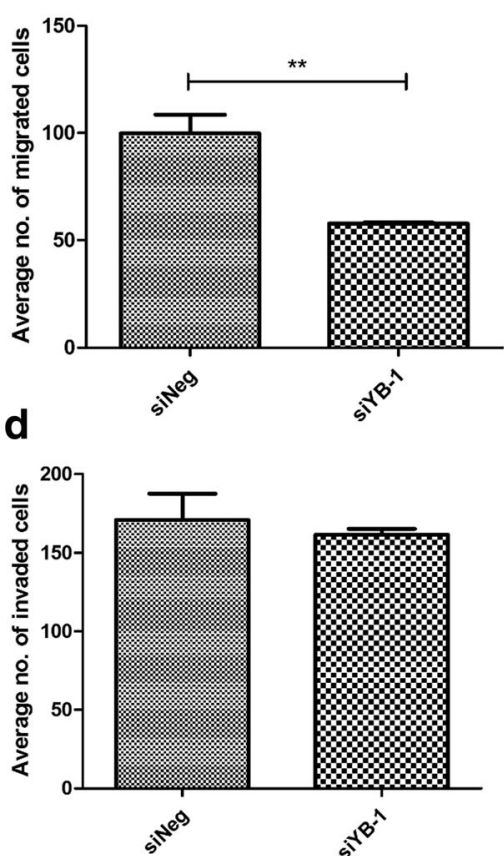
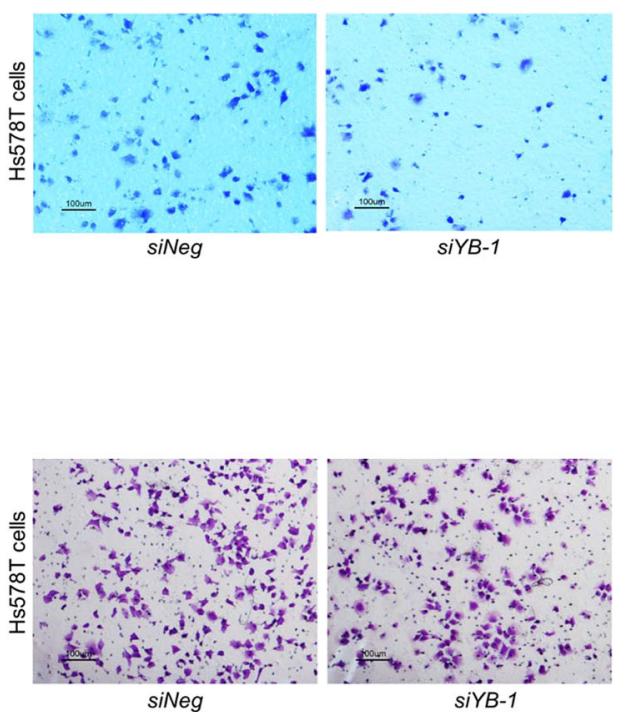

Fig. 2 YBX1 silencing in Hs578T cells inhibited cell migration but not cell invasion. a-b Knockdown of YBX1 in Hs578T breast cancer cells decreased gene level and protein expression of YB-1. c-d YBX1 silenced cells showed a a concomitant reduction in cell migration and a downward trend for cell invasion. Error bar $=\mathrm{SEM},{ }^{* *} p<0.01,{ }^{* * *} p<0.001$. Representative fields of the migration and invasion assay at 10X magnification are shown as well (Scale bar $\left.=100 \mu \mathrm{m}\right)$ 
protein was reduced by approximately $68 \%$ (Fig. 1b). A significant decrease in cell migration (approximately 21.2\%) (Fig. 1c) and cell invasion (55.5\%) (Fig. 1d) were observed in the $Y B X 1$ silenced MDA-MB-231 cells when compared to control (siNeg) cells.

The findings were also validated in invasive Hs578T breast cancer cells. The YB-1 transcript and protein level were successfully down-regulated following transfection with siRNA (Fig. 2a and b). There was a concomitant and significant decline in cell migration (42.3\%) (Fig. 2c), but not cell invasion (Fig. 2d) when compared to siNeg cells, although a downward trend was observed for cell invasion upon $Y B X 1$ silencing.
Global gene expression profiling identified CORO1C as a potential downstream target of YB-1

To identify potential targets of the YB-1 protein, and to unravel the molecular mechanism underlying the observed phenomena upon silencing of the $Y B X 1$ gene, global gene expression profiling using the Affymetrix GeneChip ${ }^{\odot}$ Human Transcriptome 2.0 Array was carried out in the $Y B X 1$ silenced MDA-MB-231 cells. Using a cut off value of $<-2$ and $>2$ and $p$ value of $<0.05$, a total of 8 coding genes were found to be up-regulated and 12 coding genes (excluding $Y B X 1$ ) were down-regulated in the siYB-1 MDA-MB-231 cells when compared to siNeg cells (Fig. 3a and b), which included both the annotated
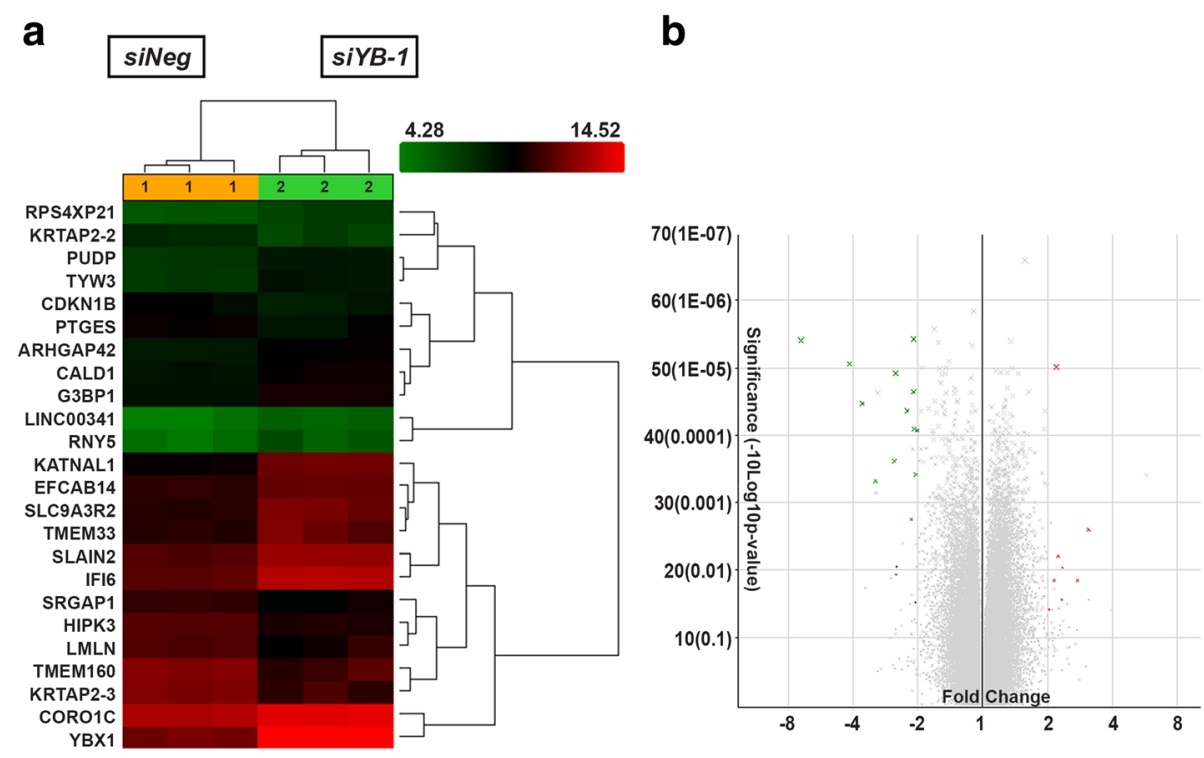

C

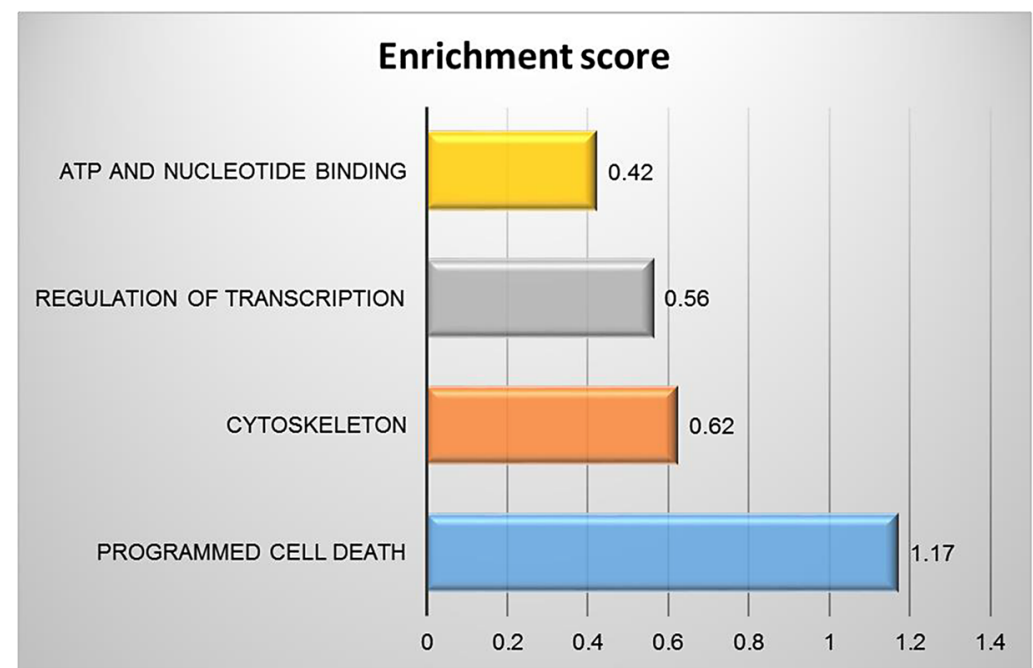

Fig. 3 Global gene expression profiling in YB-1 silenced MDA-MB-231 cells. Gene expression profiling was carried out using Affymetrix GeneChip ${ }^{\oplus}$ Human Transcriptome 2.0 Array. a Hierarchical clustering and $\mathbf{b}$ Volcano plot of the differentially expressed genes using a cut-off value of $p<0.05$ and fold change $<-2$ and $>2$. c Enrichment score of functional annotation clustering using DAVID analysis 
Table 1 List of differentially expressed annotated coding genes

\begin{tabular}{|c|c|c|c|c|c|}
\hline \multicolumn{3}{|c|}{ Down-regulated genes } & \multicolumn{3}{|c|}{ Up-regulated genes } \\
\hline Gene symbol & Fold change (siYB-1 vs. siNeg) & $p$ value & Gene Symbol & Fold change (siYB-1 vs. siNeg) & $p$ value \\
\hline YBX1 & -6.99 & 0.000004 & PTGES & 2.04 & 0.038408 \\
\hline KATNAL1 & -4.16 & 0.000009 & CDKN1B & 2.15 & 0.014217 \\
\hline$|F| 6$ & -3.63 & 0.000034 & HIPK3 & 2.2 & 0.00001 \\
\hline SLC9A3R2 & -3.15 & 0.000483 & SRGAP1 & 2.24 & 0.006231 \\
\hline TYW3 & -2.58 & 0.000243 & $L M L N$ & 2.33 & 0.027208 \\
\hline SLAIN2 & -2.54 & 0.000012 & KRTAP2-2 & 2.34 & 0.009131 \\
\hline TMEM33 & -2.52 & 0.008867 & TMEM160 & 2.75 & 0.014184 \\
\hline PUDP & -2.25 & 0.000043 & KRTAP2-3 & 3.1 & 0.00254 \\
\hline CORO1C & -2.1 & 0.000023 & & & \\
\hline G3BP1 & -2.09 & 0.000004 & & & \\
\hline EFCAB14 & -2.09 & 0.000081 & & & \\
\hline CALD1 & -2.05 & 0.000385 & & & \\
\hline ARHGAP42 & -2.02 & 0.000085 & & & \\
\hline
\end{tabular}

a

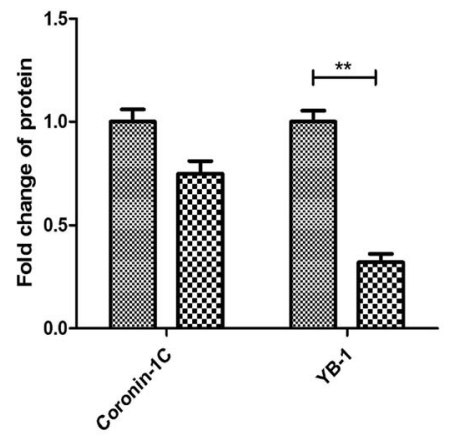

b

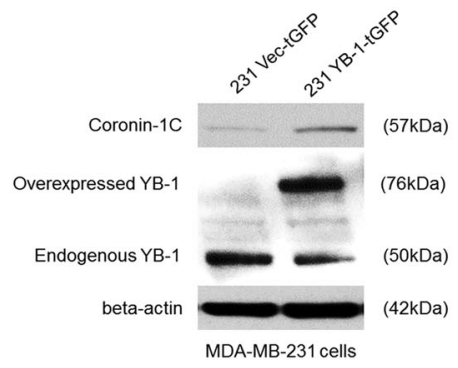

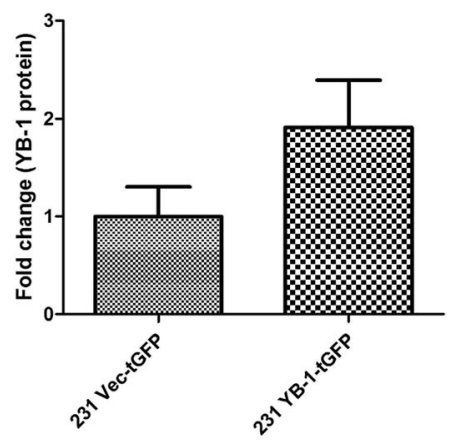

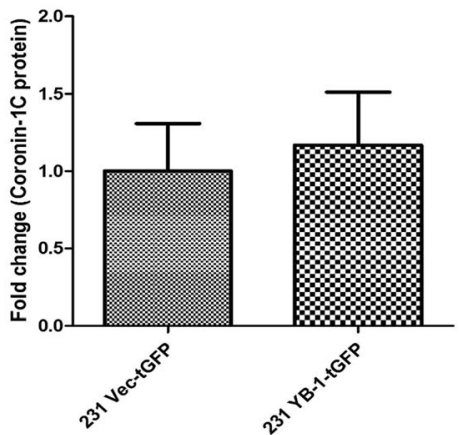

Fig. 4 Coronin-1C protein expression is dependent on YB-1 protein expression. a Coronin-1C protein expression was decreased when YB-1 was knocked down in MDA-MB-231 cells. b Coronin-1C protein expression was increased when YB-1 protein was overexpressed in MDA-MB-231 cells. Error bar $=\mathrm{SEM},{ }^{* *} p<0.01$, indicates statistically significant difference. Representative samples of Western blots are shown as well 
non-coding and coding genes. Table 1 shows the list of annotated coding genes that were differentially expressed. Additional file 2: Table S2 shows three noncoding genes that were differentially expressed.

To validate the accuracy of the microarray data, expression of the highest differentially expressed genes was quantitated by qPCR. All the genes analyzed showed a consistent pattern with the microarray results (Additional file 3: Figure S1a), suggesting that the microarray data was highly reliable and reproducible. DAVID analysis of the differentially regulated genes identified these genes as highly enriched for cytoskeleton (Fig. 3c), suggesting that
YB-1 protein could participate in the regulation of cytoskeletal structures, leading to changes in cell migration or invasion, which corroborates with the results obtained.

Subsequently, the protein expression of some differentially expressed genes, which have been shown to be involved in cancers and may play a role in migration and invasion in breast cancer, was screened by Western blot in $Y B X 1$ silenced MDA-MB-231 cells (Additional file 3: Figure S1b), and coronin-1C was then selected for further investigation. The protein expression of coronin-1C was found to be decreased when YB-1 was silenced (Fig. 4a and Additional file 3: Figure S1b). Conversely,

\section{a}

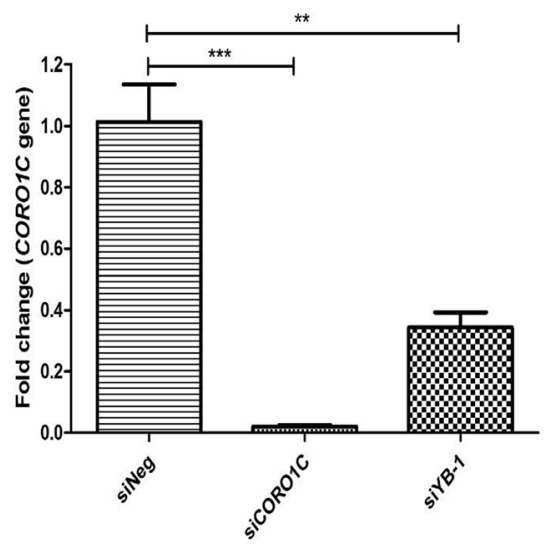

b

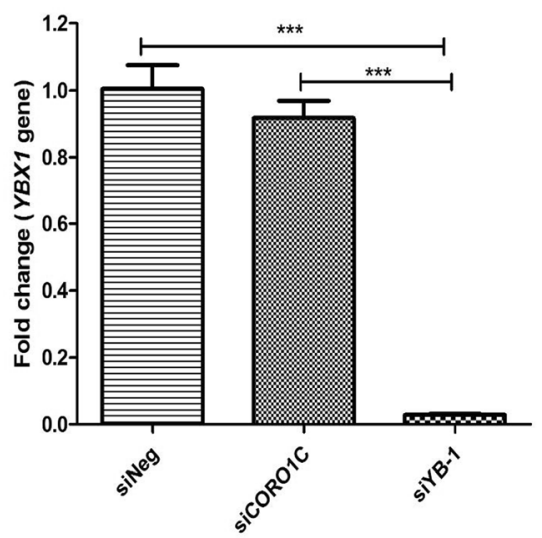

c

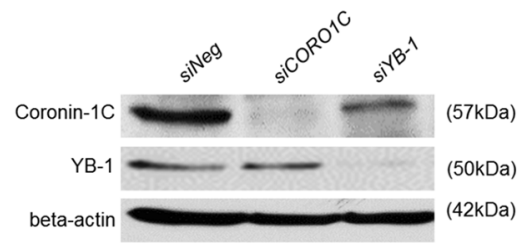

MDA-MB-231 cells
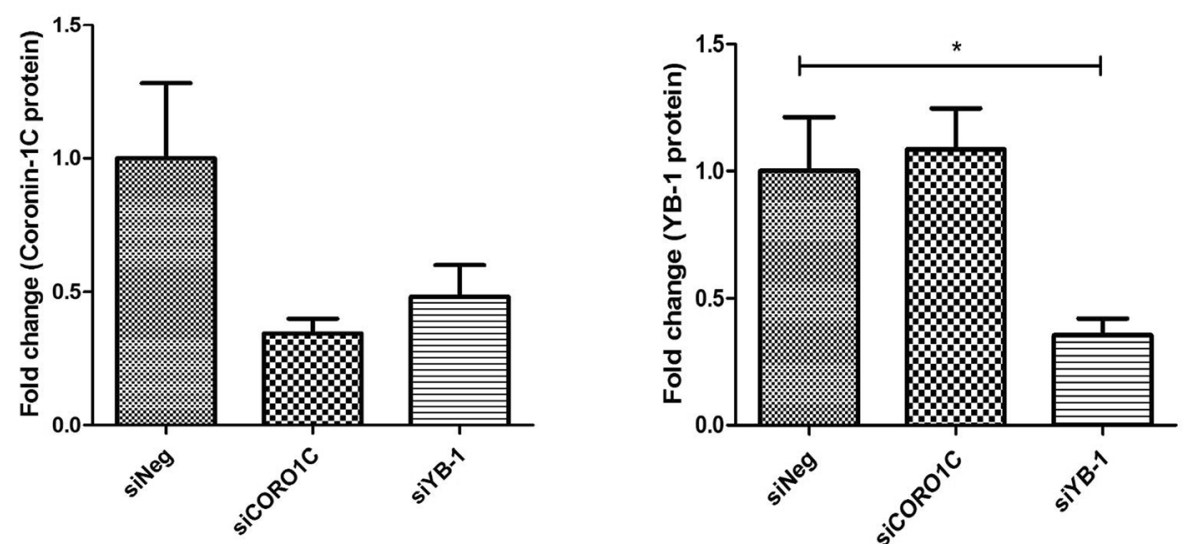

Fig. 5 Coronin-1C is a downstream target of YB-1. a Gene expression of CORO1C upon silencing of YBX1 or CORO1C. $\mathbf{b}$ Gene expression of YBX1 upon silencing of YBX1 or CORO1C. c Representative images of Western blot showing the expression of coronin-1C and YB-1 proteins. There is a decrease in CORO1C gene or protein expression upon silencing of CORO1C or YBX1 when compared to siNeg cells in MDA-MB-231 cell line. In contrast, YBX1 gene and protein expression were decreased in siYB-1 MDA-MB-231 cells only, indicating that coronin-1C is a likely downstream target of YB-1. Error bar $=\mathrm{SEM},{ }^{*} p<0.05,{ }^{* *} p<0.01,{ }^{* *} p<0.001$, indicates statistically significant difference 


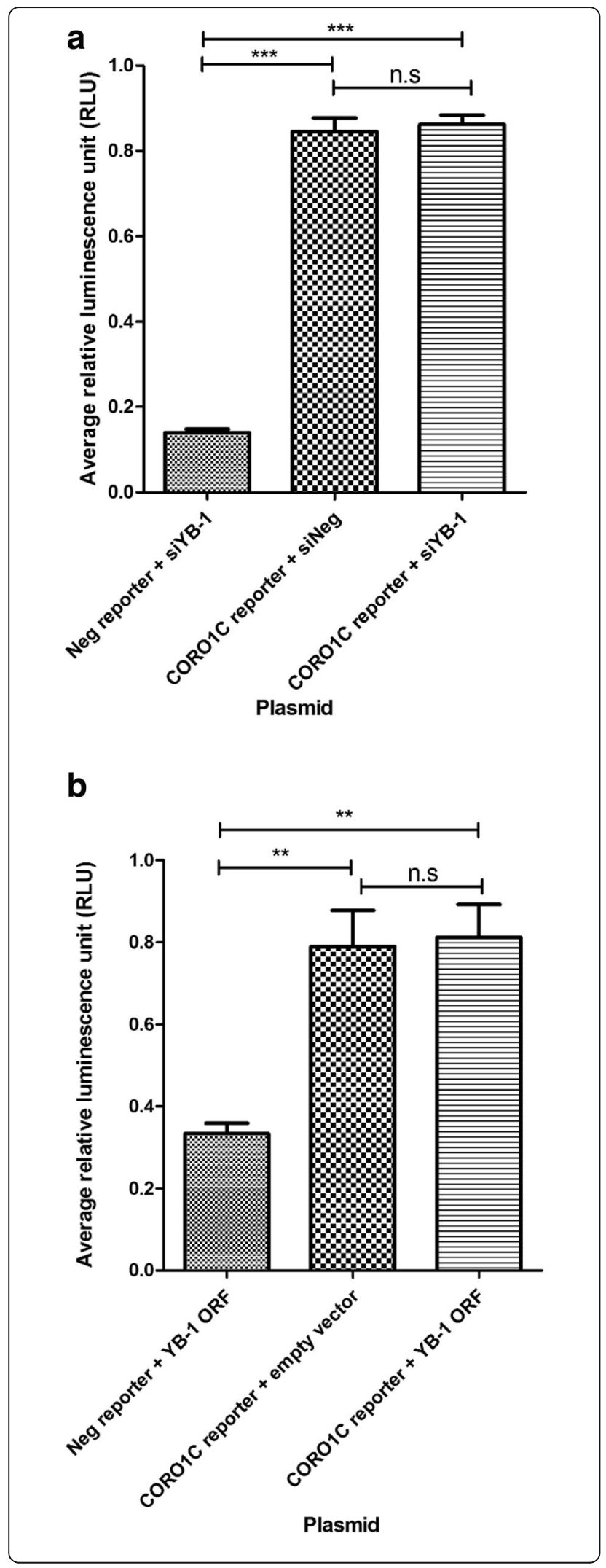

Fig. 6 CORO1C is an indirect target of YB-1. a Gaussia luciferase reporter assay revealed no significant difference in the average relative luminescence signal (RLU) between cells co-transfected with CORO1C promoter construct and siNeg or siYB-1 cells. b Gaussia luciferase reporter assay showed no significant difference in average RLU between the cells co-transfected with CORO1C promoter construct and YB-1 ORF plasmid or empty vector backbone. These results indicate that YB1 does not bind directly to the CORO1C promoter. Error bar = SEM, ${ }^{* *} p<0.01,{ }^{* * *} p<0.001$, indicates statistically significant difference

YB-1 overexpression in the MDA-MB-231 cells induced a modest increase in coronin-1C expression (Fig. 4b), suggesting that coronin-1C is likely to be a downstream target of YB-1 protein. While down-regulation of YB-1 alone reduced expression of the CORO1C gene and protein concomitantly (Fig. 5a and c), knockdown of CORO1C alone did not alter the gene and protein expression of YB-1 (Fig. 5b and c), further validating that coronin-1C is a downstream target of YB-1.

To determine whether YB-1 directly regulates CORO1C at the transcriptional level, the Gaussia luciferase reporter assay was performed. However, there was no reduction in luciferase signal after YB-1 silencing (Fig. 6a). The RLU signal was found to be significantly increased upon cotransfection of the CORO1C promoter reporter construct with both the YB-1 ORF plasmid or empty vector backbone in contrast to co-transfection of the negative promoter construct with the YB-1 ORF plasmid in MDA-MB-231 cells (Fig. 6b). Hence, the results suggest that YB-1 does not regulate transcription of CORO1C in a direct manner.

The same biological effect was also elicited in Hs578T cells, whereby silencing of the $Y B X 1$ gene in Hs578T cells also resulted in a concomitant decrease in the gene (54.3\%) and protein expression of coronin-1C (66.9\%) (Fig. 7a-c) but knockdown of CORO1C alone did not alter the protein expression of YB-1 (Fig. 7d).

siRNA- mediated silencing of CORO1C inhibits cell migration and invasion

Silencing of CORO1C induced a significant decrease in cell migration (52.6\%) (Fig. 8a) and cell invasion (63.9\%) (Fig. 8b) in MDA-MB-231 breast cancer cells. Similar findings were also observed in siCORO1C-treated Hs578T cells (Fig. 9).

siRNA-mediated YB-1- silencing in CORO1C overexpressing cells decreased cell migration and invasion

To further substantiate the notion that YB-1 could regulate cell migration and invasion through coronin-1C, a rescue experiment was carried out by silencing $Y B X 1$ in CORO1C overexpressing MDA-MB-231 cells. Coronin$1 \mathrm{C}$ overexpression induced a marked increase in cell migration and invasion (Fig. 10), which were attenuated 


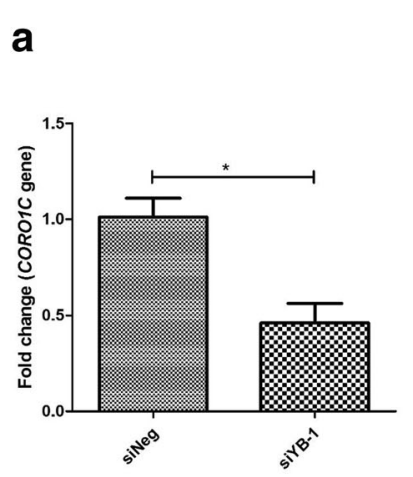

b
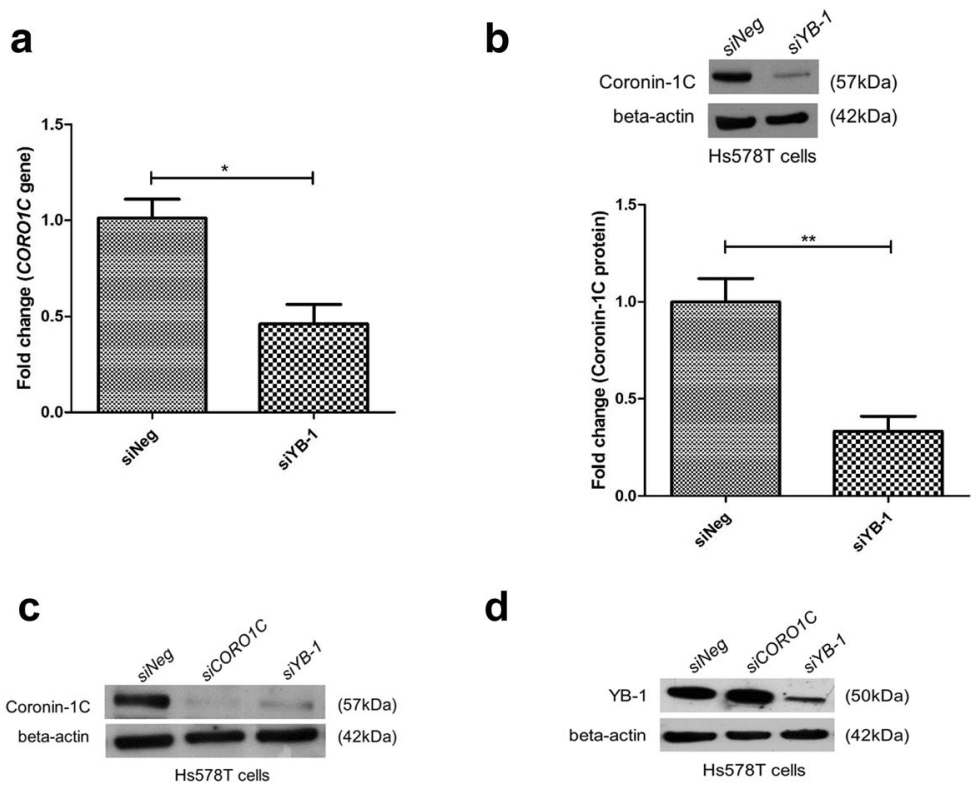

d
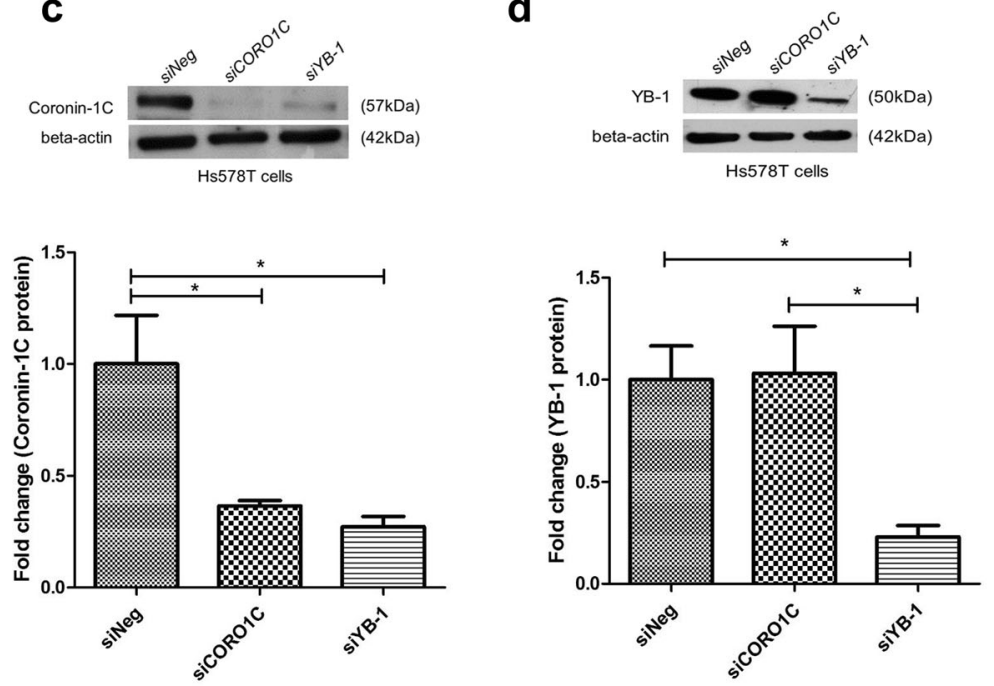

Fig. 7 YB-1 silencing decreased coronin-1C expression in the highly invasive Hs578T breast cancer cell line. a-b CORO1C gene level and protein expression of coronin-1C decreased when YBX1 was knocked down in Hs578T cells. c-d Protein expression of coronin-1C and YB-1 in either CORO1C or YB-1 silenced Hs578T cells. Error bar $=\mathrm{SEM},{ }^{*} p<0.05,{ }^{* *} p<0.01$, indicates statistically significant difference

by the knockdown of $\mathrm{YB}-1$ in the CORO1C overexpressing cells.

\section{Discussion}

Metastasis, the leading cause for cancer related deaths, is regulated by diverse molecular pathways in cancer cells and involves a complex multi-step process collectively termed as the 'invasion-metastasis cascade' [2]. YB1 has been found to promote a metastatic phenotype in breast cancer [17], gastric cancer [7, 18] and prostate cancer [19]. Moreover, YB-1 has been suggested to be an independent predictor of liver metastasis and relapse in patients with advanced gastric cancer [18]. In addition, YB-1 is overexpressed in the majority of triple-negative breast cancers (TNBC), which belongs to a highly aggressive subtype of breast cancer [20]. Hence, to obtain a better understanding of the functional role(s) of YB-1 in breast cancer metastasis, the $Y B X 1$ gene was knocked down in two highly aggressive TNBC cell lines, namely MDA-MB-231 and Hs578T cells. Knockdown of YB-1 in MDA-MB-231 cells led to a decrease in both the migration and invasive potential of the breast cancer cells. Our results are in line with a previous study where YB-1 was observed to mediate migratory and invasive properties of MDA-MB-231 cells [17].

Gene expression profiling in $Y B X 1$ silenced MDAMB-231 cells was performed to identify potential targets of YB-1 that are important in metastasis. Interestingly, from the functional annotation clustering of the differentially expressed genes, cytoskeleton proteins were found to be highly enriched. One of the fundamental steps for metastasis is the ability of cancer cells to migrate or invade, which is driven by actin re-modelling, formation of protrusions and cell adhesion that are mediated by 


\section{a}
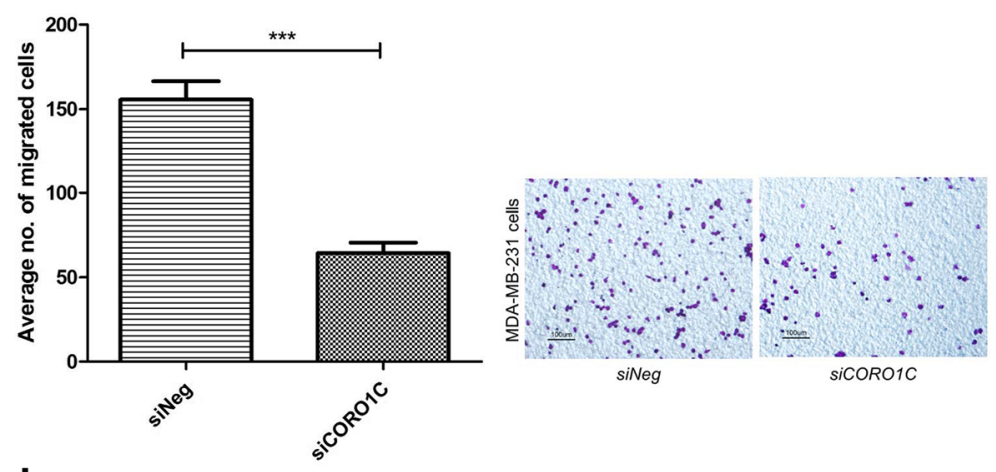

b
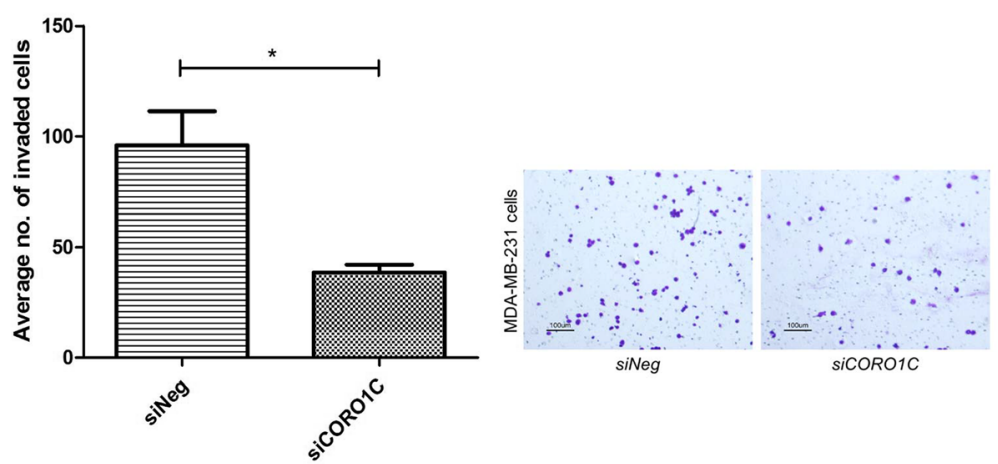

Fig. 8 CORO1C silencing in MDA-MB-231 cells reduced cell migration and invasion. $\mathbf{a}-\mathbf{b}$ Cell migration and invasion were significantly inhibited in the siCORO1C-treated MDA-MB-231 cells. Error bar $=\mathrm{SEM},{ }^{*} p<0.05,{ }^{* *} p<0.001$, indicates statistically significant difference. Representative fields of the migration and invasion assay at 10X magnification are shown as well (Scale bar $=100 \mu \mathrm{m}$ )

several proteins [21]. Actin re-modelling is mediated by several proteins such as N-WSAP, Arp2/3 complex, cofilin and coronins $[22,23]$. The role of actin re-modelling and its regulators in cancer metastasis has been widely studied [24, 25]. Nevertheless, much remains to be elucidated with regard to the exact mechanisms or genes that regulate actin re-modelling, resulting in acquisition of migratory or invasive abilities by cancer cells, a key step in cancer metastasis. Furthermore, the YB-1 protein has been observed to bind to actin and tubulin, and promote microtubule assembly [26]. YB-1 may therefore regulate different structural components of the cytoskeleton.

Our results showed that the expression of coronin-1C was dependent on the expression of YB-1 but not viceversa (in both MDA-MB-231 cells and Hs58T cells), suggesting that coronin-1C is a likely downstream target of YB-1. Coronin-1C (also known as Coronin 3) is a member of the coronin family of actin-binding proteins that regulate re-modelling of actin filaments and thus control cell migration which relies on actin dynamics [27, 28]. Coronins are known to co-localise with F-actin [29]. They recruit Arp2/3 complex to ATP-F-actin, and inhibit cofilin, thus preventing disassembly at the fast growing ends (plus end) of cells, and facilitating assembly of actin filaments. However, coronins also recruit cofilin to the slow growing ends (minus end), with the opposite effect of favoring disassembly of actin filaments [30]. These mechanisms result in elongation of the cell membrane at the leading edge, and retraction of the cells at the rear-end, thereby facilitating cell migration and even invasion.

As we were interested in metastasis-related proteins, we focused on proteins highly enriched for cytoskeletonrelated function as shown by the DAVID functional annotation analysis. Coronin- $1 \mathrm{C}$ was selected for further investigation as this protein has been associated with metastasis in a variety of cancers, including breast cancer [31] and other malignancies such as lung [32], diffuse glioma [29], hepatocellular carcinoma [33] and gastric cancer [25]. Furthermore, expression of coronin$1 \mathrm{C}$ which is known to be highest in the TNBC subtype, has been reported to correlate with lower survival [31]. Recently, microRNA-206 (miR-206) was found to reduce cell migration in MDA-MB-231 and SUM159 TNBC cell lines, by regulating the expression of its target gene, coronin-1C [31]. Moreover, overexpression of coronin-1C was found to correlate with lymph node spread and increased clinical stage in gastric carcinoma, 

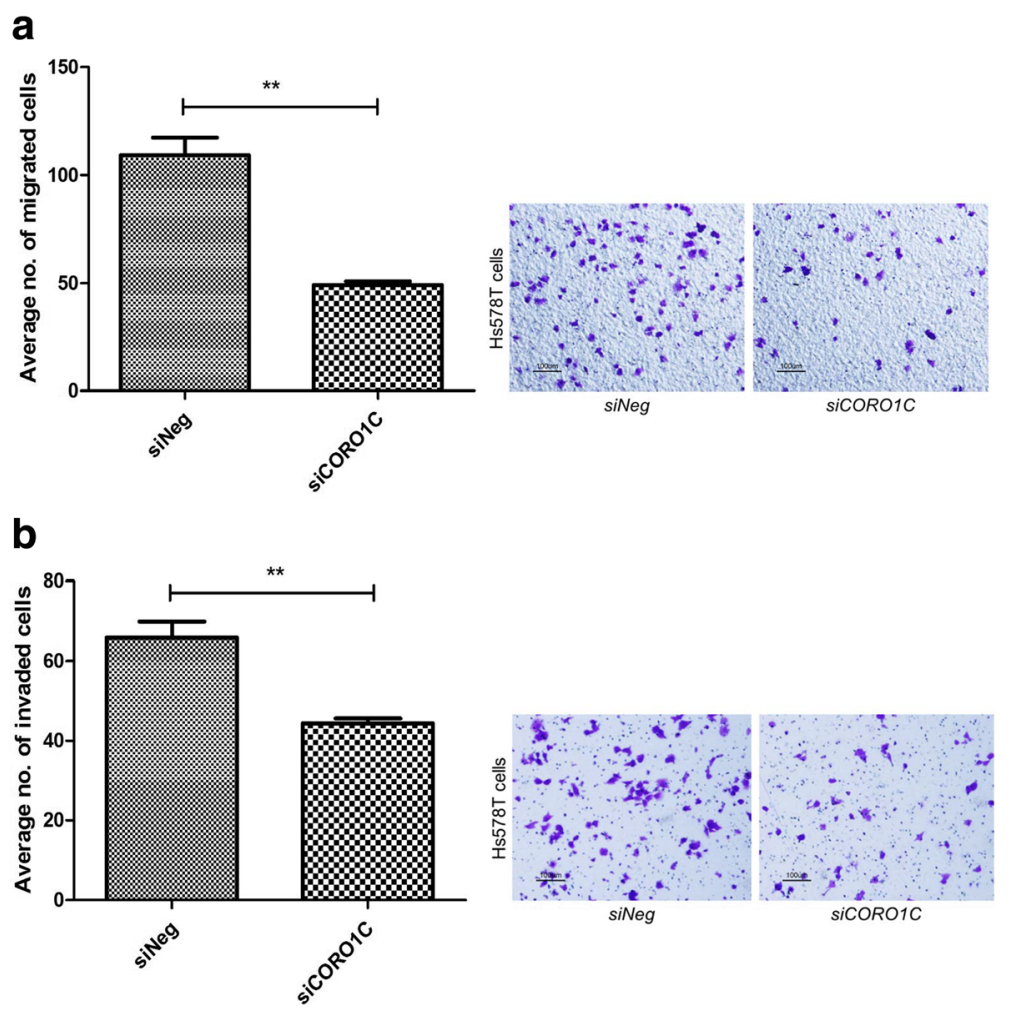

Fig. 9 CORO1C silencing in Hs578T cells inhibited cell migration and invasion. a-b Cell migration and invasion were significantly reduced in siCORO1C-treated Hs578T cells. Error bar $=\mathrm{SEM},{ }^{* *} p<0.01$. Representative fields of the migration and invasion assay at 10X magnification are shown as well (Scale bar $=100 \mu \mathrm{m})$

possibly via the regulation of MMP-9 and cathepsin K [25]. In diffuse glioma, silencing of coronin-1C led to reduced invadopodia formation, migration and invasion [24]. Taken together, these findings suggest the importance of elevated coronin-1C in tumour progression and metastasis. The other interesting differentially expressed genes that were found to be enriched for cytoskeletonrelated function as analysed by DAVID in this present study, were CALDI, KRTAP2-2 and KRTAP2-3. CALDI, which encodes for caldesmon, a versatile protein that binds to actin, myosin, calmodulin and tropomyosin, is involved in cell motility [34] and regulates metastasis of gastric cancer [35]. KRTAP2-2 and KRTAP2-3 belongs to the hair keratin-associated proteins (KRTAPs) family which form major structural components of the hair shaft with no known function in cancer cells [36]. Another differentially expressed gene identified, encodes the Rho GTPase activating protein, which is also known to be involved in the regulation of cell motility and cytoskeletal dynamics [37]. It may therefore be compelling to determine the association of YB-1 with these genes and their roles in breast cancer metastasis.

To the best of our knowledge, this is the first time that YB-1 has been demonstrated to drive breast cancer metastasis (cell migration and/or invasion) via coronin-1C.
Silencing of YB-1 or coronin-1C in MDA-MB-231 cells resulted in decreased cell migration and cell invasion, suggesting that YB-1 regulates these cellular processes via coronin-1C. Moreover, we observed a similar phenotype upon $Y B X 1$ silencing in the invasive Hs578T cells, including significant reduction in cell migration and a downward trend for cell invasion (although not significant). The latter observation could be due to the different gene expression profiles of the two cell lines as MDA-MB-231 cells are derived from an adenocarcinoma while Hs578T cells are derived from a carcinosarcoma [38]. In addition, the decrease in cell migration and invasion observed upon YB-1 silencing in coronin-1C overexpressed cells, further confirmed our hypothesis that YB-1 plays an important role in regulating cell migration and invasion through regulation of coronin-1C expression. The luciferase reporter assay revealed that coronin$1 \mathrm{C}$ is an indirect target of YB-1, suggesting that other intermediary proteins may also be involved. It is worth noting that some of the differentially expressed genes from the microarray analysis included non-coding genes such as long non-coding RNA. A previous report has found that non-coding RNAs such as microRNAs are directly involved in the transcriptional regulation of coronin-1C in breast cancer [31]. As non-coding genes 
a
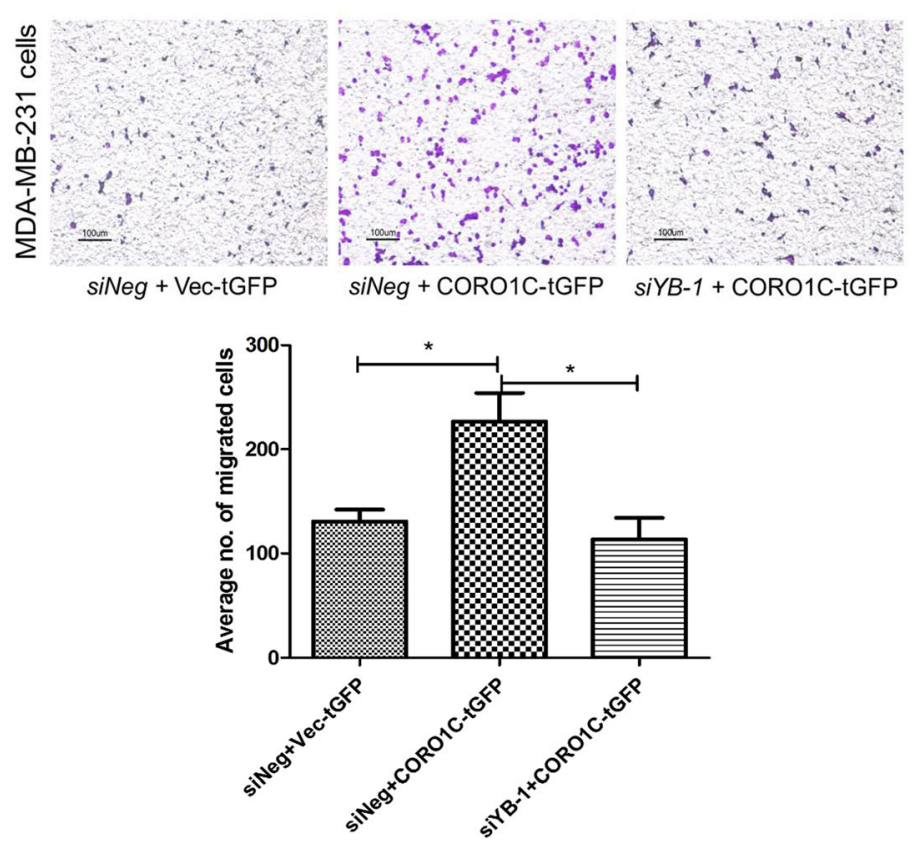

b
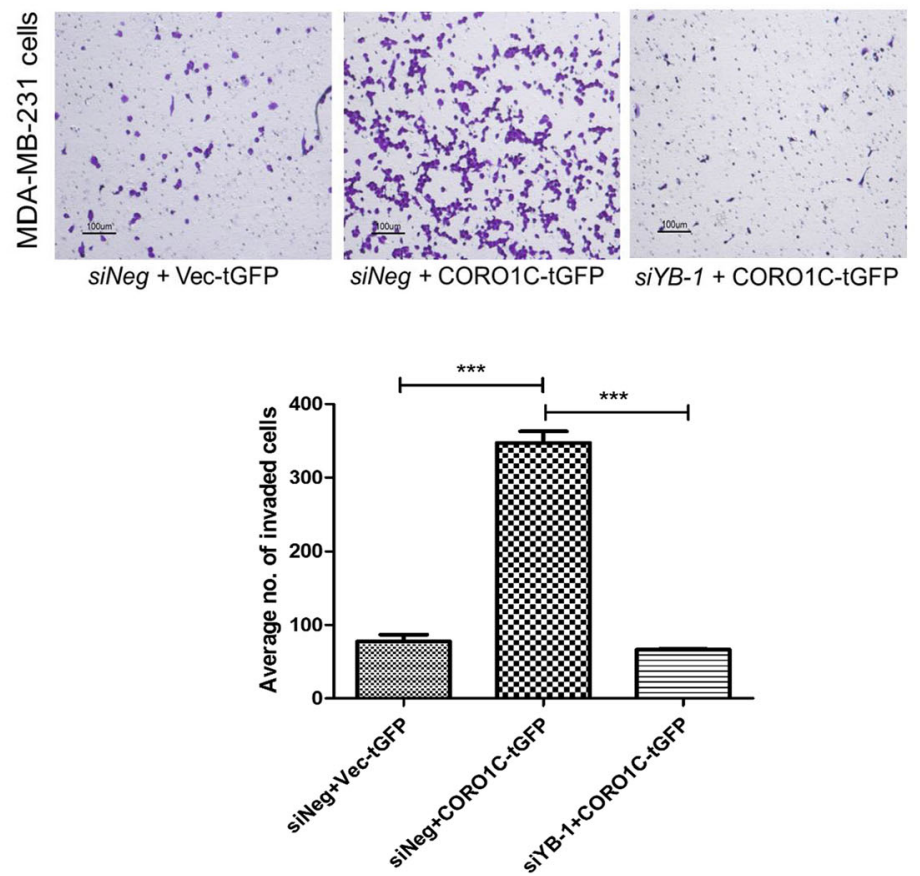

Fig. 10 a-b Silencing of $Y B X 1$ gene in coronin-1C overexpressing MDA-MB-231 cells decreased cell migration and invasion. Error bar $=$ SEM, ${ }^{*} p<0.05,{ }^{* * *} p<0.001$. Representative fields of the migration and invasion assay at 10X magnification are shown (Scale bar $\left.=100 \mu \mathrm{m}\right)$

were not part of the focus in this study, we did not further evaluate in-depth the roles of these genes. Several studies have also shown that silencing CORO1C decreases both cell invasion and migration [24, 25, 29, 32], which is consistent with our findings, thus suggesting its therapeutic and prognostic potential.

\section{Conclusion}

In conclusion, the association between $\mathrm{YB}-1$ and coronin-1C provides a novel pathway which could be a potential therapeutic target in breast cancer metastasis. Overexpression of $\mathrm{YB}-1$ and coronin-1C observed in TNBC suggests the need for more comprehensive 
investigation of this association. Future identification of intermediate proteins that are involved in YB-1 regulated coronin-1C could provide further biological insights regarding the metastatic cascade, with the possibility of identifying reliable biomarkers of early metastasis.

\section{Additional files}

Additional file 1: Table S1. Sequences of primers used for $\mathrm{QPCR}$. (XLSX $12 \mathrm{~kb}$ )

Additional file 2: Table S2. Non-coding genes that were differentially expressed following YB-1 silencing in MDA-MB-231 cells. (XLSX $10 \mathrm{~kb}$ )

Additional file 3: Figure S1. a Selected genes were used to validate the microarray data analysis using GPCR and the expression of all of the genes showed consistent patterns when compared to the microarray data. $b$ Protein expression of some differentially expressed genes were screened by Western blotting in YBX1 silenced MDA-MB-231 cells and the representative blot is shown. (TIFF $403 \mathrm{~kb}$ )

\section{Abbreviations}

siRNA: small interfering RNA; TNBC: triple-negative breast cancer; WHO: World Health Organisation; YB-1: Y-box binding protein-1

\section{Acknowledgements}

Not applicable.

\section{Funding}

This research was supported by Ministry of Education Grant (MOE2013-T2-1129). Jia Pei Lim is a recipient of the Ong Hin Tiang Scholarship in Cancer Research. The funders had no role in experimental design, data collection, analysis and interpretation of data, in preparation of the manuscript or in the decision to submit the manuscript for publication.

\section{Availability of data and materials}

The datasets supporting the conclusions of this article are included within the article. Datasets analysed during the current study can be made available from the corresponding author on reasonable request.

\section{Authors' contributions}

JPL participated in the design of the study, performed the in vitro assays, data analysis, and drafted the manuscript. SS participated in the design of the study, data analysis and contributed to the writing of the manuscript. OJS conducted the microarray analysis. JG and KM helped in the design of this study and gave critical comments on the manuscript. BHB conceived and designed the study and finalized the manuscript. All authors read and approved the final manuscript.

\section{Competing interests}

The authors declare that they have no conflict of interest.

\section{Consent for publication}

Not applicable.

Ethics approval and consent to participate

Not applicable.

\section{Publisher's Note}

Springer Nature remains neutral with regard to jurisdictional claims in published maps and institutional affiliations.

\section{Author details}

'Department of Anatomy, Yong Loo Lin School of Medicine, National University of Singapore, 4 Medical Drive, Blk MD10, Singapore 117594 , Singapore. ${ }^{2}$ Quantitative Proteomics Group, Institute of Molecular and Cell Biology, Agency for Science, Technology and Research, 61 Biopolis Drive, Proteos, Singapore 138673, Singapore. ${ }^{3}$ Laboratory of Cellular Biochemistry, RIKEN, 2-1 Hirosawa, Wako, Saitama 351-0198, Japan.
Received: 2 August 2016 Accepted: 10 March 2017

Published online: 16 March 2017

\section{References}

1. Ferlay J, Soerjomataram I, Dikshit R, Eser S, Mathers C, Rebelo M, Parkin DM, Forman D, Bray F. Cancer incidence and mortality worldwide: sources, methods and major patterns in GLOBOCAN 2012. Int J Cancer. 2015;136(5): E359-86.

2. Valastyan S, Weinberg RA. Tumor metastasis: molecular insights and evolving paradigms. Cell. 2011;147(2):275-92.

3. Weigelt B. Peterse $\mathrm{JL}$, van 't Veer $\mathrm{L}$ : Breast cancer metastasis: markers and models. Nat Rev Cancer. 2005;5(8):591-602.

4. Heimann R, Hellman S. Individual characterisation of the metastatic capacity of human breast carcinoma. Eur J Cancer. 2000;36(13):1631-9.

5. Eliseeva IA, Kim ER, Guryanov SG, Ovchinnikov LP, Lyabin DN. Y-box-binding protein 1 (YB-1) and its functions. Biochemistry (Mosc). 2011;76(13):1402-33.

6. Gimenez-Bonafe P, Fedoruk MN, Whitmore TG, Akbari M, Ralph JL, Ettinger $\mathrm{S}$, Gleave ME, Nelson CC. YB-1 is upregulated during prostate cancer tumor progression and increases P-glycoprotein activity. Prostate. 2004;59(3):337-49.

7. Guo TT, Yu YN, Yip GW, Matsumoto K, Bay BH. Silencing the YB-1 gene inhibits cell migration in gastric cancer in vitro. Anat Rec (Hoboken). 2013; 296(6):891-8.

8. Guo T, Yu Y, Yip GW, Baeg GH, Thike AA, Lim TK, Tan PH, Matsumoto K, Bay $\mathrm{BH}$. Y-box binding protein 1 is correlated with lymph node metastasis in intestinal-type gastric cancer. Histopathology. 2015;66(4):491-9.

9. Tay WL, Yip GW, Tan PH, Matsumoto K, Yeo R, Ng TP, Kumar SD, Tsujimoto $M$, Bay BH. Y-Box-binding protein-1 is a promising predictive marker of radioresistance and chemoradioresistance in nasopharyngeal cancer. Mod Pathol. 2009;22(2):282-90.

10. Janz M, Harbeck N, Dettmar P, Berger U, Schmidt A, Jurchott K, Schmitt M, Royer HD. Y-box factor YB-1 predicts drug resistance and patient outcome in breast cancer independent of clinically relevant tumor biologic factors HER2, UPA and PAI-1. Int J Cancer. 2002;97(3):278-82.

11. Bergmann S, Royer-Pokora B, Fietze E, Jurchott K, Hildebrandt B, Trost D, Leenders F, Claude JC, Theuring F, Bargou R, et al. YB-1 provokes breast cancer through the induction of chromosomal instability that emerges from mitotic failure and centrosome amplification. Cancer Res. 2005;65(10):4078-87.

12. Ohga T, Uchiumi T, Makino Y, Koike K, Wada M, Kuwano M, Kohno K. Direct involvement of the Y-box binding protein YB-1 in genotoxic stress-induced activation of the human multidrug resistance 1 gene. J Biol Chem. 1998; 273(11):5997-6000.

13. Inoue I, Matsumoto K, Yu Y, Bay BH. Surmounting chemoresistance by targeting the Y-box binding protein-1. Anat Rec (Hoboken). 2012;295(2): 215-22.

14. Lovett DH, Cheng S, Cape L, Pollock AS, Mertens PR. YB-1 alters MT1-MMP trafficking and stimulates MCF-7 breast tumor invasion and metastasis. Biochem Biophys Res Commun. 2010;398(3):482-8.

15. Evdokimova $\mathrm{V}$, Tognon $\mathrm{C}, \mathrm{Ng} \mathrm{T}$, Ruzanov $\mathrm{P}$, Melnyk $\mathrm{N}$, Fink $\mathrm{D}$, Sorokin A, Ovchinnikov LP, Davicioni E, Triche TJ, et al. Translational activation of snail1 and other developmentally regulated transcription factors by YB-1 promotes an epithelial-mesenchymal transition. Cancer Cell. 2009; 15(5):402-15.

16. Livak KJ, Schmittgen TD. Analysis of relative gene expression data using real-time quantitative PCR and the 2(-Delta Delta C(T)) Method. Methods. 2001;25(4):402-8.

17. Castellana B, Aasen T, Moreno-Bueno G, Dunn SE, Ramon YCS. Interplay between YB-1 and IL-6 promotes the metastatic phenotype in breast cancer cells. Oncotarget. 2015;6(35):38239-56.

18. Wu Y, Yamada S, Izumi H, Li Z, Shimajiri S, Wang KY, Liu YP, Kohno K, Sasaguri Y. Strong YB-1 expression is associated with liver metastasis progression and predicts shorter disease-free survival in advanced gastric cancer. J Surg Oncol. 2012;105(7):724-30.

19. Khan Ml, Adhami VM, Lall RK, Sechi M, Joshi DC, Haidar OM, Syed DN, Siddiqui IA, Chiu SY, Mukhtar H. YB-1 expression promotes epithelial-tomesenchymal transition in prostate cancer that is inhibited by a small molecule fisetin. Oncotarget. 2014;5(9):2462-74.

20. Habibi G, Leung S, Law JH, Gelmon K, Masoudi H, Turbin D, Pollak M, Nielsen TO, Huntsman D, Dunn SE. Redefining prognostic factors for breast cancer: YB-1 is a stronger predictor of relapse and disease-specific survival than estrogen receptor or HER-2 across all tumor subtypes. Breast Cancer Res. 2008;10(5):R86. 
21. Fernando HS, Kynaston HG, Jiang WG. WASP and WAVE proteins: vital intrinsic regulators of cell motility and their role in cancer (review). Int J Mol Med. 2009;23(2):141-8.

22. Chan KT, Creed SJ, Bear JE. Unraveling the enigma: progress towards understanding the coronin family of actin regulators. Trends Cell Biol. 2011; 21(8):481-8.

23. Kessels MM, Schwintzer L, Schlobinski D, Qualmann B. Controlling actin cytoskeletal organization and dynamics during neuronal morphogenesis. Eur J Cell Biol. 2011;90(11):926-33.

24. Roadcap DW, Clemen CS, Bear JE. The role of mammalian coronins in development and disease. Subcell Biochem. 2008;48:124-35.

25. Ren G, Tian Q, An Y, Feng B, Lu Y, Liang J, Li K, Shang Y, Nie Y, Wang X, et al. Coronin 3 promotes gastric cancer metastasis via the up-regulation of MMP-9 and cathepsin K. Mol Cancer. 2012;11:67.

26. Chernov KG, Curmi PA, Hamon L, Mechulam A, Ovchinnikov LP, Pastre D. Atomic force microscopy reveals binding of mRNA to microtubules mediated by two major mRNP proteins YB-1 and PABP. FEBS Lett. 2008; 582(19):2875-81.

27. Gandhi M, Goode BL. Coronin: the double-edged sword of actin dynamics. Subcell Biochem. 2008;48:72-87.

28. Uetrecht AC, Bear JE. Coronins: the return of the crown. Trends Cell Biol. 2006;16(8):421-6.

29. Thal D, Xavier CP, Rosentreter A, Linder S, Friedrichs B, Waha A, Pietsch T, Stumpf M, Noegel A, Clemen C. Expression of coronin-3 (coronin-1C) in diffuse gliomas is related to malignancy. J Pathol. 2008;214(4):415-24.

30. Cai L, Marshall TW, Uetrecht AC, Schafer DA, Bear JE. Coronin 1B coordinates Arp2/3 complex and cofilin activities at the leading edge. Cell. 2007;128(5): 915-29.

31. Wang J, Tsouko E, Jonsson P, Bergh J, Hartman J, Aydogdu E. Williams C. miR-206 inhibits cell migration through direct targeting of the actin-binding protein coronin 1C in triple-negative breast cancer. Mol Oncol. 2014;8(8): 1690-702.

32. Mataki H, Enokida H, Chiyomaru T, Mizuno K, Matsushita R, Goto $Y$, Nishikawa R, Higashimoto I, Samukawa T, Nakagawa M, et al. Downregulation of the microRNA-1/133a cluster enhances cancer cell migration and invasion in lung-squamous cell carcinoma via regulation of Coronin1C. J Hum Genet. 2015;60(2):53-61.

33. Wu L, Peng CW, Hou JX, Zhang YH, Chen C, Chen LD, Li Y. Coronin-1C is a novel biomarker for hepatocellular carcinoma invasive progression identified by proteomics analysis and clinical validation. J Exp Clin Cancer Res. 2010;29(1):17.

34. Wang C-LA. Caldesmon and the regulation of cytoskeletal functions. In: Gunning P, editor. Tropomyosin. New York: Springer New York; 2008. p. 250-72.

35. Hou Q, Tan HT, Lim KH, Lim TK, Khoo A, Tan IBH, Yeoh KG, Chung MCM Identification and Functional Validation of caldesmon as a potential gastric cancer metastasis-associated protein. J Proteome Res. 2013;12(2):980-90.

36. Fujikawa H, Fujimoto A, Faroog M, Ito M, Shimomura Y. Characterization of the human hair keratin-associated protein 2 (KRTAP2) gene family. J Invest Dermatol. 2012;132(7):1806-13.

37. Tcherkezian J, Lamarche-Vane N. Current knowledge of the large RhoGAP family of proteins. Biol Cell. 2007;99(2):67-86.

38. Charafe-Jauffret E, Ginestier C, Monville F, Finetti P, Adelaide J, Cervera N, Fekairi S, Xerri L, Jacquemier J, Birnbaum D, et al. Gene expression profiling of breast cell lines identifies potential new basal markers. Oncogene. 2006; 25(15):2273-84.

\section{Submit your next manuscript to BioMed Central and we will help you at every step:}

- We accept pre-submission inquiries

- Our selector tool helps you to find the most relevant journal

- We provide round the clock customer support

- Convenient online submission

- Thorough peer review

- Inclusion in PubMed and all major indexing services

- Maximum visibility for your research

Submit your manuscript at www.biomedcentral.com/submit
Biomed Central 